\title{
Use of 3D visualisation tools for representing urban greenspace spatial planning.
}

WANG, C., MILLER, D., JIANG, Y. and DONALDSON-SELBY, G.

(C) 2015 IEEE. Personal use of this material is permitted. Permission from IEEE must be obtained for all other uses, in any current or future media, including reprinting/republishing this material for advertising or promotional purposes, creating new collective works, for resale or redistribution to servers or lists, or reuse of any copyrighted component of this work in other works. 


\section{Use of 3D Visualisation Tools for Representing Urban Greenspace Spatial Planning}

\author{
Chen Wang \\ Information and Computational Sciences \\ The James Hutton Institute \\ $\mathrm{UK}$ \\ chen.wang@hutton.ac.uk
}

Yang Jiang

School of Computing Science and Digital Media

The Robert Gordon University

UK

y.jiang2@rgu.ac.uk

\author{
David Miller \\ Information and Computational Sciences \\ The James Hutton Institute \\ UK \\ david.miller@hutton.ac.uk
}

\author{
Gillian Donaldson-Selby \\ Information and Computational Sciences \\ The James Hutton Institute \\ UK \\ gillian.donaldson-selby@hutton.ac.uk
}

\begin{abstract}
The objective of this paper is to report on the development of prototype models for use in raising public awareness of changes in urban areas, focusing on greenspaces, and testing responses to scenarios of change. Specifically, the focus is on the design of appropriate types of outdoor features for community planning and engagement. This modelling is fulfilled using the Autodesk Maya, Google SketchUp and ArcGIS software packages together in a novel combination of spatial and visualisation tools. The experiment results show evidence that different types of 3D iconic symbols with interactive communication will influence participation and decision making in land use planning.
\end{abstract}

Keywords-3D Visualisation, GIS, Land Use, Greenspace, Public Engagement

\section{INTRODUCTION}

The Vision of the Scottish Land Use Strategy notes that 'plans and decisions about land use deliver improved and enduring benefits, enhancing the wellbeing of our nation'. It sets out guiding principles and proposals for sustainable land use to deliver multiple benefits. Its principles include those of engaging communities in planning and decisions relating to the management of natural resources in urban and rural areas.

The application of the principles at a local level are envisaged as resulting in more consistent and integrated land use decisions. This is intended to enable a better connection of communities with the land, allowing people to positively influence land use, recognising that detailed policy implementation for different parts of Scotland requires effective local engagement processes.

The Strategy promotes the use of an ecosystem approach (EA) as a means of integrated management of land, water and living resources [28].
3D Visualisation is used as important tools in many aspects of urban design and rural planning to assist the various stakeholders' better understanding and communicating for policy decisions [15][8]. Public participation is also important for engagement in decision making, planning and feedback. The impact on the planning process depends on the level of stakeholder involvement. This involvement can be divided into three aspects as shown in [8].

There are increasingly requirements for developing tools for decision making using interactive web [2], GIS and 3D virtual environment based platforms [4][12]. Berry et al [3] propose GIS approaches which include web-based survey design and development, and landscape visualization. However, the effectiveness of this method suffers from lack of scenario-choice, multi-criteria choice experiment techniques to enhance public participation. In support of large community planning processes, the interactive CommunityViz tool with the immersive lab facilities are employed to illustrate landscape planning [11]. To orient the participants and to familiarize them with basic 3D model and dynamic viewing capabilities, participants were provided with laser pens to highlight features on the screen during the discussion. The main drawback to the process was time limitations to comprehensively investigate the CommunityViz scenarios interactively. Today, 3D software programs such as Maya, 3DS Max, Vega Prime, Octaga or specialized landscape tools Visual Nature Studio provide a high degree of visual realism for landscape, rendered both as images or animations [18][2][4][7]. Recently, Google Earth based visualization is growing rapidly as a method of sharing 3D environmental data by using combination of digital elevation models, satellite imagery, 3D buildings, trees and streets footprints [6][20][16].

This research describes the findings of engagement with local communities in a case study in Dundee identifying scenarios of potential greenspace content, use, and environments conducive to health and well-being. It is an 
example of the use of an EA in the identification of planning issues, development of scenarios of greenspace, consideration of options, and identification of preferred choices. Particularly, 3D visualisation tools were used to present multiple functions of the greenspace, communityidentified priorities and the introduction of potentially new 3D features such as dog exercise area, shelter for adults, barbeque equipment and car parking.

\section{BACKGROUND}

Visualization tools have been used to test public preferences for landscapes [9], the results of which have been interpreted in terms of visual concepts (e.g. coherence, scale/openness [17]. As noted by Schroth [23], they provide means of participation and collaboration with respect to planning, and can be used to combine spatial data and 3D features of significance to understanding the scene or context. Often the imagery used in such studies is static, and yet disturbance and ephemeral factors are recognized as being of significance with respect to public interpretation of landscapes and visual impacts of land-use change [19]. However, the significance of movement of features rarely appears to be built into tests of preferences or simulations for use in engaging the public in consultations in planning land-use change.

Recently, there is a tread to create methods and tools for testing historical scenarios through the use of 3D modelling tools and virtual reality engines[24][25] . In [26], 3D models, virtual reality and game engines are combined as a tool for reconstruction of cultural heritage [27] . It also includes artificial intelligence driven avatars. AI scripts is added to assign a set of predetermined actions and reactions which contains going for a walk or complex actions amounting to a defined daily timetable, or pre-defined dialogues.

In order to let people immersed in computer models explore landscapes of the past, present and future, virtual reality labs with big screens are necessary to take the interactive roles. The first mobile unit of its kind in the United Kingdom is the Virtual Landscape Theatre (www.hutton.ac.uk/learning/exhibits/vlt), which is used for scientific research as well as engagement with the public on issues of landscape change. Other virtual theatres such as a landscape immersive lab [14] or a virtual reality suite (www.iri-vr.ncl.ac.uk) are able to perform the same functions.

\section{Methodology}

The steps being follows are outlined below:

- Acquisition of spatial data in ArcGIS, which are processed to provide the spatial context and infrastructure.

- Assembly of GIS data and greenspace visualization

- Interactive functionality and interface for virtual green space model

- Testing the effectiveness of the models with public and professional audiences, at venues in the vicinity of the areas of study and also more remote venues.

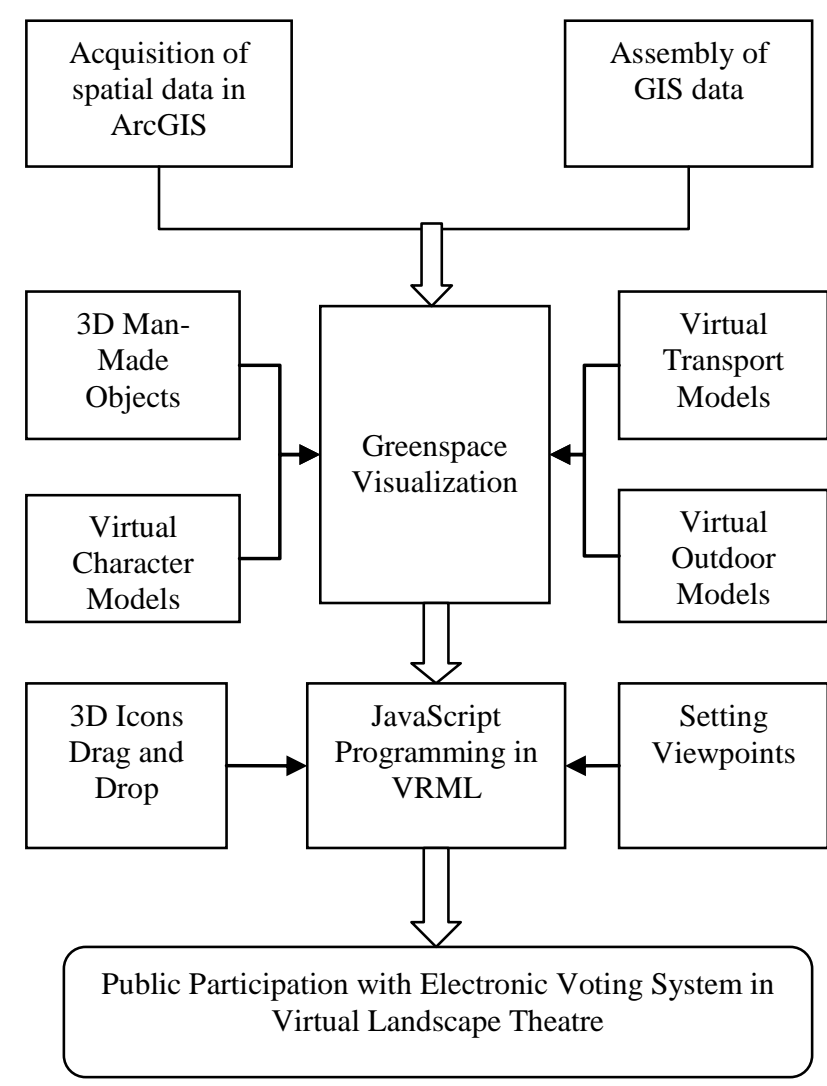

Figure 1 Framework for 3D visualization and simulation of Finlathan Park Land Use

The prototype model was used in events designed to elicit public aspirations and concerns regarding future land uses, and to develop scenarios driven by local input. Sessions comprised:

- Introducing drivers of land use change (e.g. movement of features ) and electronic voting system;

- Audiences recording preferences for greenspace from different viewpoints;

- Audiences voting to prioritise greenspace topics for in-depth discussions;

- Discussion and voting on greenspace issues (e.g. shelters location/ size; woodland location/type, barbeque equipment location/type).

\section{A. Study Area}

Our study area is the Finlathan Park (approximately 2 $\mathrm{km}^{2}$ ) in the Dundee, Scotland (Figure 2). Finlathan Park was chosen because of complementary work on the nature of engagement with urban greenspaces, and the differences in meaning to different people, and its location in proximity to an area of Dundee with medium to high levels of greenspace, and high levels of deprivation. The Dundee Open Space Strategy 2008-2011 [29] was used to identify the overall requirements of local open space in the city, such as Finlathan Park. Their functions include provision of 
recreation (formal and informal), nature conservation, visual amenity, and support frequent local use.

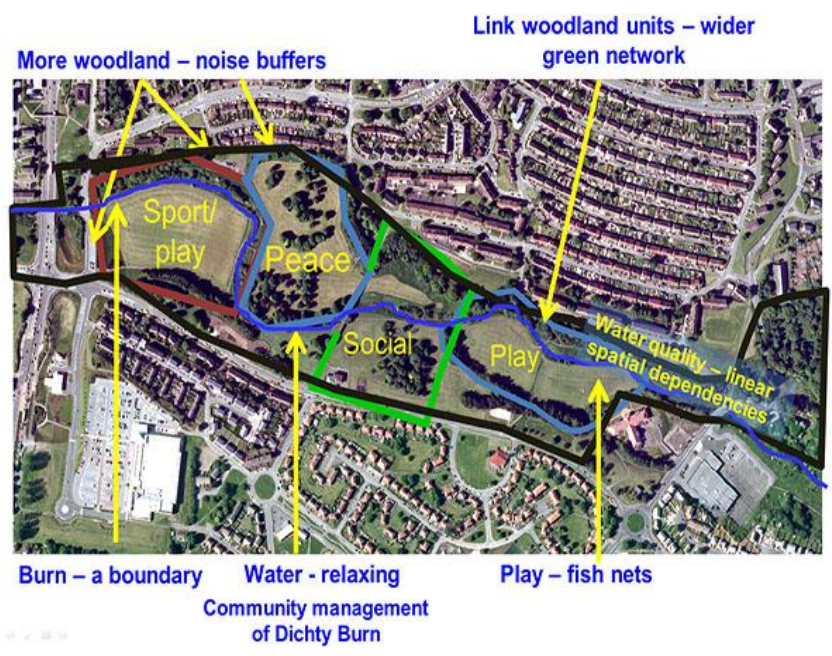

Figure 2. Example spatial plan for park and adjacent area derived from engagement events.

\section{B. Acquisition of Spatial Data in ArcGIS}

ArcGIS is used to mapping services and manage geographic information in a database. It enables us to store, use and manage all GIS data more efficiently and effectively.

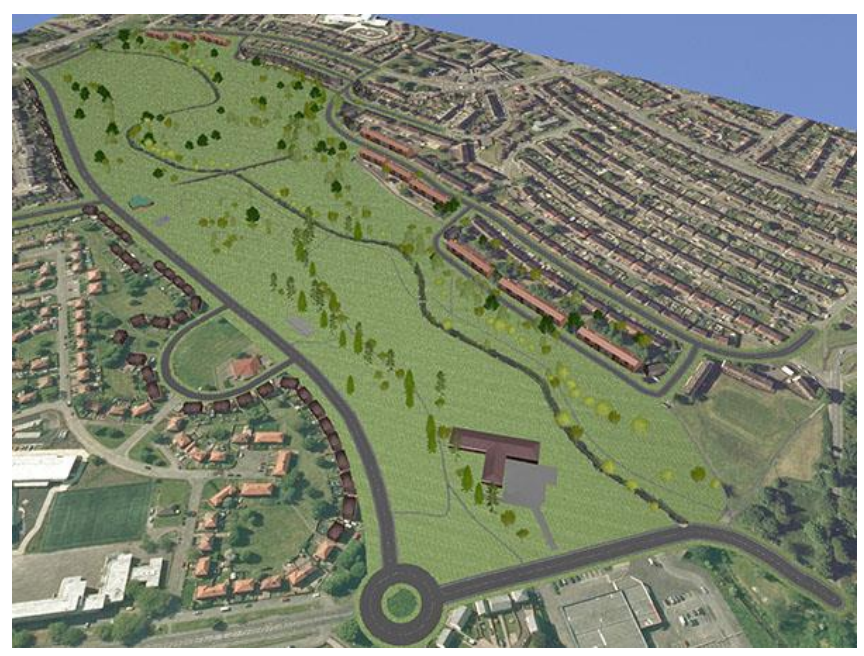

Figure 3 3D Finlathan Park model in VNS

For the first step, all GIS data need to be pre-processed in ArcGIS. Ordnance Survey contour data was used to create a Digital Terrain Model of $2 \mathrm{~km}$ x $2 \mathrm{~km}$ at a 10 metre resolution. Detailed cropping system data at field scale was derived from Integrated Agricultural Control System data (IACS 2000-2007). The Ordnance Survey aerial photography, with a resolution of $30 \mathrm{~cm}$, is used as the main terrain texture. Then, the clipped photography in ArcMap was converted to geographic TIF format and imported into Virtual Natural Studio (VNS). ArcSDE datasets are used for outlines, buildings, roads, and green and open spaces. The aerial imagery for ground textures is used to classify open spaces by using the PAN 65 Typology [12] . In the next step, VNS provides tools to control visualization directly from GIS data, simplifying and automating the process in order to create the digital Finlathan Park model.

Figure 3 shows a sample view of the prototype model of Finlathan Park, illustrating land uses, woodland and residential areas.

VNS is limited in modelling and lack of simulation function. In order to make this 3D landscape more realistic and multifunctional, it is necessary to import it into Autodesk Maya and Google SketchUp for further processing.

\section{Assembly of GIS Data and Greenspace Visualization}

This requires converting the clipped terrain contour map into a TIN (Triangulated Irregular Network), applying the clipped photography into Terrain, and then translating the footprints of buildings, trees and roads to their appropriate height. These footprints are defined in polygon, point and polyline shapefiles. For buildings, the building footprints have to be translated into their appropriate altitude, then the footprints extruded to their appropriate height. For trees, raw images are edited in Photoshop, and then two real photos are texture mapped in two orthometric planes and imported to ArcGIS. For roads, the method is to load them on the ground of the Finlathan Park terrain, and then to mark them with specific colours.

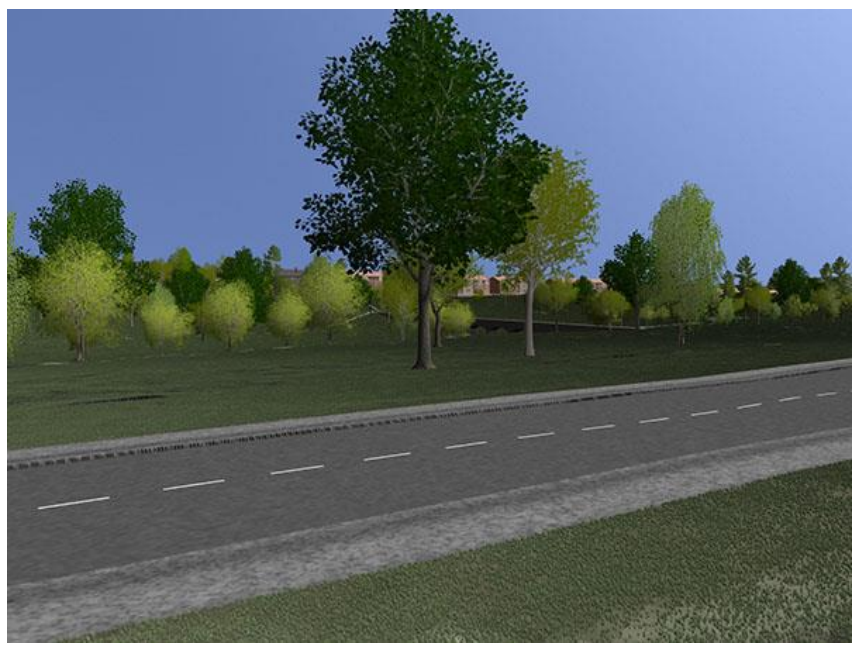

Figure 4 Detailed virtual models in Finlathan Park

VNS is used to implement these and export all GIS data to Virtual Reality Modelling Language (VRML) format to load into Maya and Google SketchUp. 3D man-made models (e.g. buildings, trees, roads, cars) were directly constructed in Google SketchUp. Other 3D objects such as bridges, street lamps, virtual character and animals were created in Autodesk Maya.

Figure 4 shows the detailed virtual models in Finlathan Park including woodland, traffic roads and residential areas. 


\section{Interactive functionality and interface for virtual greenspace model}

An interface has been developed to fit with the output of $3 \mathrm{D}$ model and the model content with respect to purpose of use. This part of the experiment focused on the interaction and usability of the interface, and the recognizability of the type of visualization (3D icons). By involving the scenarios, the participants firstly used voting equipment to choose their own interested landscape features. Their preferences for 3D icons were adapted to put in a certain position, referring to, for instance, navigation and orientation in the $3 \mathrm{D}$ environment. Examples are provided in Figure 5.
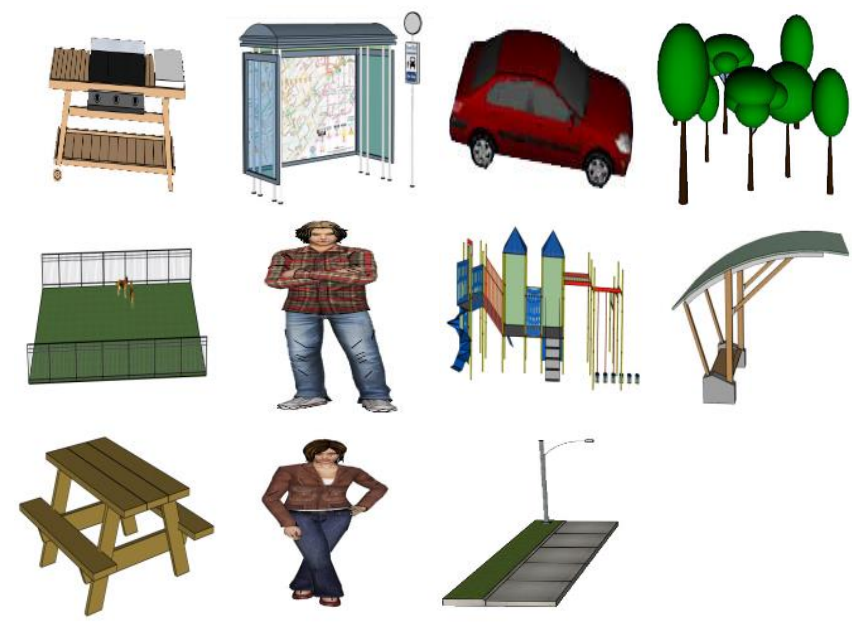

Figure 5 3D iconic symbols

The icons are coded in JavaScript to allow participants to select locations of the shelter, the dog exercise area, children's plays areas, car parking, barbeque equipment, and footpath. It also provides the functions for pointing out those sited areas where audiences definitely do not want such a feature.

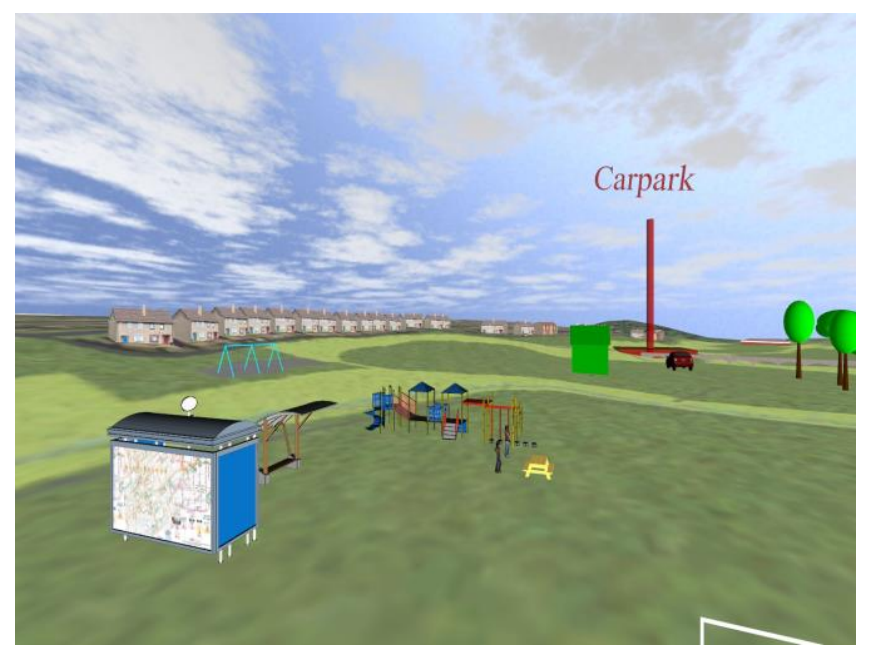

Figure 6 3D icons dragged and dropped in Finlathan Park Model

Figure 6 shows how Finlathan Park can be populated according to local participant's preferences.
E. Testing the Effective of Models with Public and Professional Audiences

Qualitative interviews are being used to obtain feedback on the contribution made by the inclusion of movement within a scene, in relation to: (i) the types of features include; (ii) the characteristics of their movement; (iii) views of the scene from fixed positions, or from the virtual human or vehicle; (iv) visual legibility of the scene; (v) credibility of the features.

Models representing alternative land uses were used in the VLT [21] with electronic voting designed to elicit public aspirations and concerns regarding future land uses, and to develop scenarios driven by local input. The process involved people answering questions about their current uses of this or other parks, and constraints, motivations and changes in patterns of use.

Figure 7 shows public participation regarding Finlathan Park planning in the future.

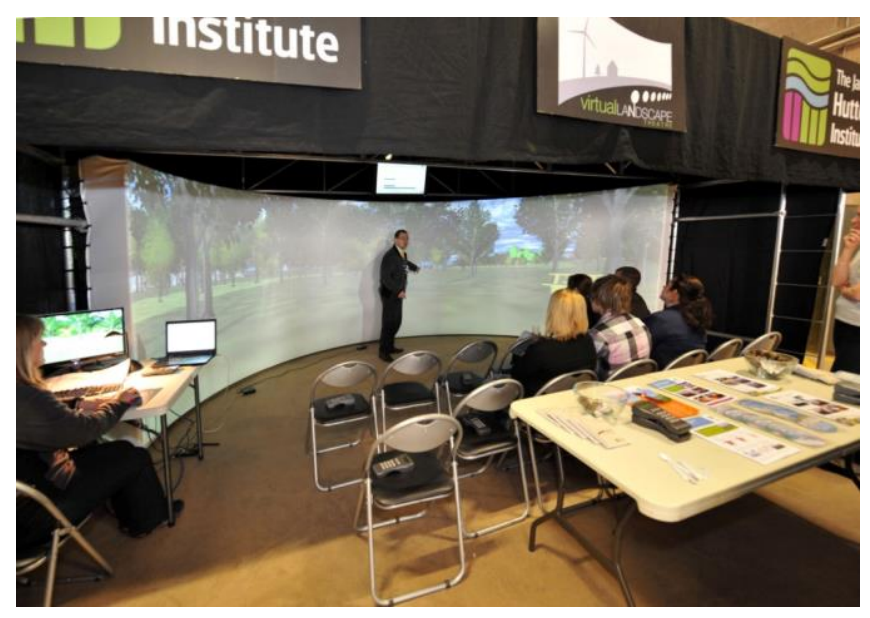

Figure 7 Eliciting public opinions on current and alternative future uses of Finlathan Park, Dundee, in the Virtual Landscape Theatre, with audiences from Dundee.

The findings have potential implications for the planning and design of greenspaces to increase the effectiveness of their use, and contribution to wider green infrastructure, as envisaged in the European Biodiversity Strategy to 2020. Community recognition of potential multiple benefits from greenspace such as relaxation and destressing, biodiversity, and as a focal feature to adjacent or local communities, supports the aims of the Scottish Planning Policy in respect of open space audits and strategies, recognising the community value of greenspace, the quality of the space and the diversity of current uses. That in turn supports the European Environment Strategy towards 2020 which recognises multiple benefits from nature integrated through spatial planning into sustainable management.

The results are being used to inform the design of tools for eliciting public responses to prospective changes in land use in urban and peri-urban environments, including development of small-scale renewable energy and changes in urban greenspaces. 


\section{CONCLUSIONS}

We propose a new combination approach for representation and assessment of greenspace model in land planning and management, which is based on ArcGIS, Google Sketchup and Autodesk Maya. This work seeks to demonstrate the application of several of the Land Use Strategy Principles: (a) encouraging opportunities for multiple benefits from land use; (b) opportunities for outdoor recreation and public access to land should be encouraged, with the provision of greenspace close to where people live, given their importance for health and well-being; (c) people should have opportunities to contribute to debates and decisions about land use and management decisions which affect their lives and their future.

\section{ACKNOWLEDGMENT}

This research was funded by the Scottish Government GreenHealth project on "Contribution of green and open space in public health and well-being". Thanks also to participants in the City of Dundee who contributed to the research.

\section{REFERENCES}

[1] Aubrecht, C., K. Steinnocher, M. Hollaus, and W. Wagner, 2009, "Integrating earth observation and GIScience for high resolution spatial and functional modeling of urban land use", Computers, Environment and Urban Systems, 33(1), p. 15-25

[2] Ball, J., N. Capanni, and S. Watt, 2008, "Virtual reality for mutual understanding in landscape planning", International Journal of Social Sciences, 27(2), 78-88.

[3] Berry, R., G. Higgs, R. Fry, and M. Langford, 2011, "Web-based GIS Approaches to Enhance Public Participation in Wind Farm Planning", Transactions in GIS, 15(2), p. 147-172.

[4] Bishop, I.D. and D.R. Miller, 2007, Visual assessment of off-shore wind turbines: the influence of distance, contrast, movement and social variables, Renewable Energy, 32, p. 814-831.

[5] Bulmer, D., 2001, "How can computer simulated visualizations of the built environment facilitate better public participation in the planning process?" Online Planning Journal, p. 1-43.

[6] Butler, D., 2006, "Virtual globes: the web-wide world", Nature, 439, p. $776-778$.

[7] Donaldson-Selby G, Wang C, Miller D et al, "Testing Public Preferences for Future Land Uses and Landscapes", Proceedings of the GIS Research UK 20th Annual Conference, pp.139-144, 2012. ISBN: 978-1-86220-294-8

[8] Miller, D.R., J. Morrice, P. Horne, and J. Ball, 2007, "Integrating programmes of awareness and education for professionals and the Public", Proceedings of Environment 2007, Abu Dhabi.

[9] Ode, A., G. Fry, P. Messager, D. Miller and M. Tveit, 2009, "Indicators of perceived naturalness as drivers of landscape preference", Journal of Environmental Management 90(1), p. 375383.

[10] Ordnance Survey, 2012, MasterMap Topography Layer, www.ordnancesurvey.co.uk/oswebsite/products/osmastermap/topogra phy-layer/index.html.
[11] Salter, J., C. Campbell, M. Journeay, and S. Sheppard, 2009, "The digital workshop: Exploring the use of interactive and immersive visualisation tools in participatory planning", Journal of Environmental Management, 90, p.2090-2101.

[12] Scottish Government, 2008, "Planning and Advice Note 65 Planning and Open spaces". http://www.scotland.gov.uk/Publications/2008/05/30100623/0.

[13] Shen, Z. and M. Kawakami, 2010, "An online visualization tool for Internet-based local townscape design", Computers, Environment and Urban Systems, 34(2), p. 104-116.

[14] Sheppard, S.R.J., D. Cavens, J. Salter and M.J. Meitner, 2001, Seeing the big picture: the benefits of digital landscape immersion, in: Proceedings of 2001 ASLA Annual Meeting and EXPO, Montreal.

[15] Smith, R.S. and M. Craglia, 2003, "Digital participation and access to geographic information: A case study of local government in the United Kingdom”, URISA Journal, 15, 49-54.

[16] Tiede, D. and S. Lang, 2010, "Analytical 3D views and virtual globes - scientific results in a familiar spatial context", ISPRS Journal of Photogrammetry and Remote Sensing, 65(3), p. 300-307.

[17] Tveit M., A. Ode, and G. Fry, 2006, Key visual concepts in a framework for analyzing visual landscape character, Landscape Research 31(3), p.229-255.

[18] Wang. C, T.R. Wan and I.J. Palmer, "Automatic reconstruction of 3D environment using real terrain data and satellite images", Intelligent Automation and Soft Computing, TSI, 18(1), p. 49-63, 2012.

[19] Wergles, $\mathrm{N}$ and A. Muhar, "The role of computer visualization in the communication of urban design - A comparison of viewer responses to visualizations versus on-site visits". Landscape and Urban Planning, 91, p. 171-182, 2009

[20] Wright, T.E, M. Burton, D.M. Pyle, and T. Caltabiano, 2009, "Visualising volcanic gas plumes with virtual globes", Computers \& Geosciences, 35(9), p. 1837-1842.

[21] VLT, http://www.hutton.ac.uk/learning/exhibits/vlt

[22] Wang, C., Donaldson-Selby, G., Miller, D.R., Horne, P., Morrice, J.G. and Howe, J, "Public interpretation of land and sea use using visualisation tools", GIS Research UK, University of Liverpool, 3-5 April 2013.

[23] Schroth, O, 2010, From information to participation: interactive visualisation as a tool for collaborative planning, Instituts für Raumund Landscaftsenwicklung ETH Zurich.

[24] Vasáros, Z., 2008. Authenticity and accuracy of virtual reconstructions - a critical approach. In: CAA2008 Session - On the Road to Reconstructing the Past, Programs and Abstracts, Budapest, Hungary, April 2-6, pp. 249. ISBN: 978-963-8046-95-6.

[25] Verhagen, P., 2008. Dealing with uncertainty in archaeology. In: CAA2008 Session - On the Road to Reconstructing the Past, Programs and Abstracts, Budapest, Hungary, April 2-6, pp. 99. ISBN: 978-963-8046-95-6.

[26] Helena Rua and Pedro Alvito 2011, "Living the past: 3D models, virtual reality and game engines as tools for supporting archaeology and the reconstruction of cultural heritage -the case-study of the Roman villa of Casal de Freiria", Journal of Archaeological Science, Volume 38, Issue 12, December 2011, Pages 3296-3308

[27] Bethesda Softworks,2011; (a ZeniMax Media company), The Elder Scrolls_ IV: Shivering Isles_(Oblivion).

[28] UNEP/CBD/COP/10/27 (2010). Report of the Tenth Meeting of the Conference of the Parties to the Convention on Biological Diversity COP 10, Japan, October 2010.

[29] Dundee Partnership (2008). Dundee Public Open Space Strategy 2008 - 2011, Dundee partnership, pp. 33 (www.dundeecity.gov.uk/dundeecity/uploaded_publications/publicati on_957.pdf 